\title{
FOUCAULT E BLANCHOT: UM DIÁLOGO POSSÍVEL A PARTIR DA AUSÊNCIA DE OBRA E DO ESQUECIMENTO
}

\author{
Daniel Verginelli Galantin ${ }^{1}$ \\ Universidade Federal do Paraná (UFPR) \\ (iD) http://orcid.org/0000-0003-3833-7955
}

\begin{abstract}
RESUMO:
Após uma análise do final de História da loucura, propomos uma leitura do artigo de Blanchot sobre este livro com o objetivo de explorar um diálogo possível entre ambos os autores. Defendemos que o tema de fundo deste diálogo é a relação entre pensamento e esquecimento. A questão que guia este diálogo concerne à possibilidade da construção de um pensamento que caminharia em direção a um tipo de esquecimento ativo e não de uma falta da memória. Defendemos a hipótese de que a reflexão blanchotiana sobre o esquecimento, ainda que situada num espaço de pensamento diferente daquele de Foucault quanto a conceitos, metodologia e objetos, pode ajudar a compreender a noção de ausência de obra, tal como ela aparece ao final de História da loucura. Ademais, também consideramos que tal noção repercute na obra foucaultiana posterior, mesmo que ela não seja literalmente retomada. Defendemos que tal repercussão concerne especialmente à questão da relação entre o trabalho de Foucault e o presente, bem como argumentamos que o diálogo com Blanchot pode ajudar a pensar a ontologia crítica do presente enquanto esforço de esquecimento ativo do presente e de si mesmo.
\end{abstract}

PALAVRAS-CHAVE: Esquecimento; Ausência de obra; Crítica; Ética; Política.

\section{FOUCAULT AND BLANCHOT: A POSSIBLE DIALOGUE THROUGH WORKLESSNESS AND FORGETFULNESS}

\footnotetext{
${ }^{1}$ Doutorando em Filosofia pela Universidade Federal do Paraná (UFPR), Paraná - Brasil. E-mail: d.galantin@gmail.com
} 


\begin{abstract}
:
After an anylisis of the end of History of madness, we propose an interpretation of Blanchot's article about it. Our aim is to examine a possible dialogue between them. We defend that the theme which might organize such a dialogue is that of forgetfulness and it's relation with thought. The guiding question is the possibility of a tought that would march towards an active kind of forgetfulness, which isn't just the result of memory's fault. We defend the hypothesis that the blanchotian consideration on forgetfulness might help to understand that of 'absence of work' which appears in the end of History of madness ; even though blanchotian thought situated in a space of thought very different from that of Foucault, as the case of it's concepts, methodology and objects. In the same way, this notion could reverberate more vastly in foucaultian works, even though it won't be resumed after. We think that such a repercussion concern specially the question of the relation between Foucault's own researches and the present itself ; and that the dialogue with Blanchot could help to think the critic of the present as an effort to actively forget the present and also oneself.
\end{abstract}

KEYWORDS : Fogetfulness ; Worklessness ; Critics ; Ethics ; Politics.

\title{
O círculo antropológico: o espelho de Narciso e o pensamento enlouquecido
}

Ao final de História da loucura, Foucault apresenta uma narrativa histórica da constituição da loucura enquanto doença mental através daquilo que é denominado enquanto "o círculo antropológico" (FOUCAULT, 2012, p.505). Diferentemente do século XVII, quando a loucura era considerada puro erro, não-ser e inumanidade a ser expulsa para fora da sociedade, ao final do XVIII, a partir de uma multiplicidade de acontecimentos, a constituição da loucura deixa de ser considerada a partir de uma estrutura binária de exclusão com relação à racionalidade e passa a ser entrevista sob uma estrutura ternária, constituída pela tríade homem-loucura-verdade. Nesse contexto, a alteridade representada pela loucura não é mais excluída, mas sim internalizada pela razão, de modo a tornar-se uma forma de mediação para o reconhecimento do homem razoável com relação a si mesmo.

Se entre os séculos XVII e XVIII a linguagem do louco não tinha qualquer importância, sendo considerada enquanto simples erro, a partir do final do XVIII a fala do alienado mostrará ao homem normal, a partir da distância segura dos sabres psi,

uma linguagem onde o homem aparece na loucura como sendo outro que ele-mesmo. Mas nessa alteridade ele revela a verdade que ele é ele-mesmo, e isto indefinidamente, no movimento tagarela da alienação. O louco não é mais o insensato no

Foucault e Blanchot: um diálogo possível a partir da ausência de obra e do esquecimento - Daniel Verginelli Galantin 
espaço segregado da desrazão clássica; ele é o alienado na forma moderna da doença. Nessa loucura o homem não é mais considerado numa espécie de afastamento absoluto com relação à verdade; ele é nela a sua verdade e o contrário de sua verdade. Ele é ele-mesmo e outra coisa que ele-mesmo; ele é considerado na objetividade do verdadeiro, mas é verdadeira subjetividade $^{2}$ (FOUCAULT, 2012, p.520).

Em resumo, temos aqui o movimento através do qual o outro que é louco deixa de ser uma alteridade absoluta, porém reduzida a nada e expulsa da vida social, para tornar-se um outro do mesmo, um alter ego que é muito mais ego do que alter, uma instância de mediação entre o homem são e sua própria verdade, numa trajetória através da qual ele pode conhecer e ter consciência de si mesmo.

No entanto, esta experiência narcísica da loucura não é absoluta, posto que no coração da modernidade também existem formas de pensamento que se desconectaram do círculo antropológico. Tanto em alguns quadros de Goya, quanto nos escritos do Marquês de Sade ou de Artaud, podemos encontrar, respectivamente, sejam as figuras da ausência no fundo negro de onde emergem as figuras nos quadros, seja a possibilidade de eliminação da humanidade por uma natureza tornada criminosa, sejam palavras atormentadas pelo vazio de seu centro. Para Foucault, ao invés dessas formas de pensamento fazerem a mediação do reconhecimento do homem normal com relação a si mesmo, ao invés de fazerem parte de sua subjetivação através da objetivação da loucura, elas são uma forma de quebra deste espelho de Narciso, jogando este homem para fora de si-mesmo. Assim, tais formas de pensamento fabricam fissuras no mundo que corresponde a tal homem.

A relação entre loucura e obra na modernidade acompanha a mesma estrutura especular, porém com uma diferença fundamental devido à linguagem que lhes concerne. Se a loucura passa a dizer a verdade do homem, no caso das obras acima mencionadas a loucura diz a verdade da obra. Mas Foucault detecta: loucura é ausência de obra. Assim, a ausência de obra será a verdade da obra, de maneira que nas obras de Sade e Goya estamos diante de figuras da desrazão em que homem e mundo desaparecem num movimento de apagamento remetido à ausência de obra. Logo, a noção de ausência de obra presente nas últimas páginas da tese de Foucault remete a este sentido de interrupção ou de uma margem exterior que, de certo modo, assim como ameaça a constituição acabada do mundo moderno, também ameaça o acabamento de toda obra.

Desta maneira, ainda que em sua tese Foucault não explique minuciosamente o que ele compreende por ausência de obra, a leitura das últimas páginas de História da Loucura nos permite pensá-la enquanto

\footnotetext{
${ }^{2}$ Em todas as citações de História da loucura fizemos pequenas alterações na tradução para facilitar a leitura de acordo com o encadeamento da língua portuguesa.
}

Foucault e Blanchot: um diálogo possível a partir da ausência de obra e do esquecimento - Daniel Verginelli Galantin 
espaço de abolição da obra, margem que se abre para aquilo que não é mais ela mesma, signo de sua incompletude ou inacabamento, aquilo que a comunica com seu outro num jogo de proximidade e distância ameaçador e sem reconciliação. E isso é justamente aquilo que a constitui enquanto obra. Segundo Foucault,

\begin{abstract}
a loucura é ruptura absoluta da obra; ela forma o momento constitutivo de uma abolição que funda no tempo a verdade da obra; ela esboça sua margem exterior [nosso grifo], a linha de desabamento, o perfil contra o vazio. A obra de Artaud faz na loucura a experiência [éprouve] de sua própria ausência, mas essa provação [épreuve], a coragem recomeçada desse desafio [épreuve], todas essas palavras jogadas contra uma ausência fundamental da linguagem, todo esse espaço de sofrimento físico e de terror que margeia o vazio ou, antes, coincide com ele, aí está a própria obra: o escarpamento sobre o vazio da ausência de obra (FOUCAULT, 2012, p.529).
\end{abstract}

É por esta razão que, para Foucault, não importa definir quando Nietzsche tornou-se realmente louco, ou quais eram os momentos de sanidade de Artaud, para separarmos o que é material clínico do que é filosofia ou teatro. Pois a loucura destes personagens não apenas é constitutiva de suas obras, como é também "aquilo através do que este pensamento se abre sobre o mundo moderno" (FOUCAULT, 2012, p.529). Tal gesto de Foucault implica em algo simples, porém cheio de consequências: considerar que a loucura é capaz de pensamento, e mais especificamente de um pensamento que coloque o mundo e o homem moderno em questão - por isso separar loucura de obra para poder identificar cada uma delas seria o mesmo que reinseri-las no círculo antropológico ${ }^{3}$. A partir de tal consideração, pensamos que, ao avaliar os motivos da diminuição do interesse de Foucault pela literatura na década de 1970, o coletivo de autores do prefácio da compilação La grande étrangère resvala para dentro de uma posição que o filósofo deliberadamente rejeitou em sua tese. Ao problematizar a "vontade" de escritores considerados doentes mentais, o prefácio acaba por desconsiderar o potencial de uso de suas escritas para dinamitar por dentro o discurso, devido à questão da sanidade mental destes (ARTIÈRES; BERT; POTTE-BONNEVILLE; REVEL, 2013, pp.16-17). Os autores deixam entrever que doentes mentais não fariam projetos e que sua vontade não seria autônoma, o que constituiria um problema para pensar o potencial político de seus escritos. Além de Foucault rejeitar a noção de projeto como orientador político ${ }^{4}$, fazer tal afirmação implica, de certa maneira, em considerar que apenas homens

\footnotetext{
${ }^{3}$ Com isso Foucault está deliberadamente contornando a decisão seiscentista de excluir a loucura do pensamento.

${ }^{4}$ Sobre isso ver os textos n.281; 293; 339; 358 (FOUCAULT, 2001b, pp.908-909; 986; 1393-1394; 1565).
}

Foucault e Blanchot: um diálogo possível a partir da ausência de obra e do esquecimento - Daniel Verginelli Galantin 
normais seriam capazes de colocar em questão uma determinada ordem do discurso (sem levar em consideração justamente que, para Foucault, tais homens razoáveis constituem-se enquanto tais a partir de uma relação de objetivação para com os alienados). Ou seja, tal afirmação implica em desconsiderar que, na própria relação com os homens sãos, aqueles que enlouqueceram seriam capazes de colocar "uma questão sem resposta onde o mundo é obrigado a interrogar-se" (FOUCAULT, 2012, p.529), questão, ademais, eminentemente ético-política. Se, como dito por Machado, Foucault nunca tentará explicar a obra pela loucura do autor, e se a definição da loucura enquanto ausência de obra é parte do esforço para contornar a perspectiva psicológica-antropológica, a qual tem como sua condição de possibilidade o enclausuramento clássico (MACHADO, 2005, pp.40-41), pensamos não ser possível diminuir o potencial político de obras de autores que enlouqueceram fazendo apelo à qualificação de suas respectivas vontades.

O próprio deslocamento de perspectiva sobre o qual se baseia História da loucura implica na renúncia do ordenamento da narrativa através do triunfo gradativo da racionalidade moderna, a qual toma a psicologia como conhecimento que finalmente desvelou a verdade da loucura como doença mental. Ao recusar partir das verdades terminais do presente para investigar a loucura, o filósofo retira o caráter necessário do aparato de saberes e instituições de cada época, mostrando que sua constituição remete a outros princípios que não uma grande história da Razão - crises econômicas, transformações religiosas e novas exigências de ordem social, por exemplo. Ao final deste trajeto ele ainda mostra como, na modernidade, as obras daqueles que uma vez enlouqueceram constituem uma experiência de pensamento capaz de dizer algo que coloca o próprio mundo moderno em questão (algo para o qual o pensamento antropológico não tem ouvidos):

doravante e através da mediação da loucura, é o mundo que se torna culpado (pela primeira vez na história ocidental) aos olhos da obra; ei-lo requisitado por ela, obrigado a ordenar-se por sua linguagem [nosso grifo], coagido por ela a uma tarefa de reconhecimento, de reparação; obrigado à tarefa de dar a razão dessa desrazão, para essa desrazão. A loucura em que a obra se arruína é o espaço de nosso trabalho, é o caminho infinito para terminá-lo, é nossa vocação mista de apóstolo e de exegeta (FOUCAULT, 2012, p.530).

Não é de pouca importância que Foucault termine sua tese com tais palavras, pois com elas situa seu próprio pensamento num espaço compartilhado com aquele aberto por tais formas de loucura. Aqui a primeira pessoa do plural não parece ser irônica ou retórica, mas sim implicar o próprio enunciador; pois a figura do apóstolo carrega consigo a recusa de Foucault em aceitar a objetivação moderna da loucura, assim

Foucault e Blanchot: um diálogo possível a partir da ausência de obra e do esquecimento - Daniel Verginelli Galantin 
como a exegese é invocada na medida em que a realização deste trabalho nunca visa separar a loucura das obras analisadas, seja como sua condição anterior ou como sua finalidade (FAVREAU, 2012, pp.86-87). Numa época caracterizada por fazer da loucura uma instância de mediação entre o homem são e sua própria verdade, tais experiências de pensamento fazem da loucura uma instância de não-reconhecimento do homem são, assim como fazem da ausência de obra o espaço de uma abolição que funda a verdade da obra. Logo, talvez também possamos dizer que estas figuras de pensamento louco são ausência de homem, pois a linguagem que elas falam não diz nem a verdade do sujeito racional que a escuta, nem a verdade daquele que fala. Sua ausência central, o fato destas linguagens tentarem se aproximar cada vez mais desse espaço vazio de auto-implicação, acaba por colocar em jogo os limites do homem ao mostrar que ele não é senhor desta linguagem, deslocando-o para fora de si mesmo. Ou seja, esta linguagem expõe o sujeito racional moderno a uma diferença ou alteração que o desestabiliza, colocando em jogo tanto a objetivação do doente mental quanto a subjetivação do sujeito normal. Talvez possamos dizer que a ausência de obra aponta para uma espécie de dessubjetivação de ambos os lados, o que mostraria seu viés ético-político: ético por interromper a constituição especular antropológica do sujeito moderno, e político porque tal constituição não existe sem um suporte institucional de internamento.

$\mathrm{Na}$ linguagem de tais formas de pensamento não há nada que justifique a experiência antropológica moderna. Ao contrário, ela coloca em jogo este aspecto da modernidade abrindo nela uma fissura a partir da qual há espaço para um presente outro. Esta interrupção do presente designada pela ausência de obra encontra-se diretamente na tese de Foucault enquanto um dilaceramento onde o mundo é obrigado a interrogar-se, um espaço de interrogação aberto pela loucura que interrompe uma obra, e que julgamos ser compartilhado pelo pensamento de Foucault. Segundo o filósofo,

\begin{abstract}
isso que quer dizer que, através da loucura, uma obra que parece absorver-se no mundo, que parece nele revelar então seu não-sentido [non-sens] e aí transfigurar-se nos traços apenas do patológico, no fundo engaja nela o tempo do mundo, domina-o e o conduz; pela loucura que a interrompe, uma obra abre um vazio, um tempo de silêncio, uma questão sem resposta, provoca um dilaceramento sem reconciliação onde o mundo é obrigado a interrogar-se (FOUCAULT, 2012, p.529).
\end{abstract}

\title{
A recepção de Blanchot: pensar, esquecer
}

Seguimos agora a pista de um artigo publicado por Maurice Blanchot em 1961 na Nouvelle Revue Française. Pensamos que ele a ponta para algo cuja importância ainda precisa ser melhor avaliada: se é verdade que Foucault se interessou por Blanchot, um movimento inverso também

Foucault e Blanchot: um diálogo possível a partir da ausência de obra e do esquecimento - Daniel Verginelli Galantin 
parece ter ocorrido ${ }^{5}$. Deste modo, ao invés de sugerir um possível diálogo através de "O pensamento do fora" (FOUCAULT, 2001a), texto que mereceria outro artigo, analisaremos "L'oubli, la déraison", de Blanchot (BLANCHOT, 2009, p.289). Neste texto Maurice Blanchot reconheceu no tema da ausência de obra uma apropriação foucaultiana da noção de "inoperância" (désoeuvrement), tematizada em $O$ espaço literário e ao final do livro L'entretien infini (BLANCHOT 2009), no texto "L'absence de livre". O texto inicia com uma de esquecimento estritamente negativa, visto que seria nem de uma presença nem uma ausência:

O esquecimento: não-presença, não-ausência. (...).

No esquecimento há aquilo que se desvia de nós e este desvio que vem do esquecimento. Relação entre o desvio da palavra e o desvio do esquecimento. Daí que uma palavra, mesmo falando a coisa esquecida, não escapa ao esquecimento, fala a favor do esquecimento (BLANCHOT, 2009, p.289).

Logo, o esquecimento apresenta uma dupla dimensão. De um lado ele é necessário a tudo aquilo que concerne à possibilidade e a um poder: é porque podemos esquecer que podemos falar utilmente, trabalhar, nos lembrarmos; enfim, estarmos vinculados a uma presença. Por outro lado, contudo, o esquecimento também escapa, e neste desvio ele desliza para fora da possibilidade. Segundo Blanchot,

Isso não significa simplesmente que uma possibilidade nos é subtraída pelo esquecimento, e que uma certa impotência é revelada; mas que a possibilidade que é o esquecimento é deslizamento para fora da possibilidade. Ao mesmo tempo em que nos servimos do esquecimento como de um poder, o poder esquecer nos remete ao esquecimento sem poder, ao movimento que esquiva e se esquiva, o próprio desvio (BLANCHOT, 2009, p.290).

Tal é a razão de sua definição estritamente negativa, pois o esquecimento não se define unicamente pela coisa esquecida (o que seria restringi-lo a uma negação determinada, a uma presença da qual ele revelaria a ausência, e a uma possibilidade); ele é também esse vazio, desvio que desestabiliza e abre um espaço de indeterminação. Desta maneira, apenas a negação pode indicá-lo na medida em que mantém sua dimensão múltipla e indefinida. Tudo isso nos mostra que não há qualquer lirismo ou manipulação hermética da linguagem quando Blanchot remete o esquecimento a uma "inarticulação do fora". Trata-se de um "movimento que se exclui e, por esta exclusão, se designa como exterior a si mesmo,

${ }^{5}$ Foucault é o único filósofo ao qual Blanchot dedicou um livro inteiro: Michel Foucault tel que je l'imagine (BLANCHOT, 1986).

Foucault e Blanchot: um diálogo possível a partir da ausência de obra e do esquecimento - Daniel Verginelli Galantin 
exigindo assim uma exterioridade nunca articulada (...)" (BLANCHOT, 2009, p.292). É por remeter a uma multiplicidade nunca circunscrita de antemão, cujas partes não estão articuladas de modo a formar uma totalidade, que o esquecimento diz respeito a uma inarticulação do fora. Este é o esforço de Blanchot para não subordinar o esquecimento à memória.

Baseando-se no primeiro prefácio da tese de Foucault, Blanchot considera o livro uma "história dos limites - destes gestos obscuros, necessariamente esquecidos uma vez realizados, através dos quais uma cultura rejeita algo que será para ela o Exterior" (FOUCAULT, 2001a, p.189). Nesta direção, a existência histórica da loucura como objeto de conhecimento possível é considerada enquanto parte de um processo tanto de enclausuramento do fora quanto de sua interiorização.

Apesar da posterior supressão deste prefácio pelo próprio Foucault, em seu artigo, Blanchot coloca duas questões-guia que acompanham de perto os momentos finais de História da loucura. Trata-se de perguntar pela possibilidade das artes e a literatura ajudarem no estabelecimento de uma relação outra com aquilo que excede nossa cultura, relação nem de exclusão e nem de interiorização especular. Tal possibilidade nos parece ilustrada pela figura da ausência de obra, definida enquanto margem exterior da obra coincidente com a loucura, a qual coloca uma questão sem resposta que obriga o mundo moderno a interrogar-se: ao mostrar que elas se ordenam por uma forma de linguagem isomorfa àquela da loucura, Foucault sugere como tais formas de arte colocam um problema quanto à constituição do homem são, obrigando-o a reconhecer que há pensamento em tais obras. Mas Blanchot ainda se pergunta se o estabelecimento dessa relação 'outra' talvez nem sequer seja circunscrito às artes, fazendo parte do próprio pensamento, venha ele de onde vier ${ }^{6}$. Assim, defendemos que Blanchot se refere ao estatuto do próprio pensamento de Foucault ao propor a segunda questão que estrutura seu artigo:

\footnotetext{
${ }^{6}$ Peter Pál Pelbart mostrou, por exemplo, como a cultura grega arcaica e mesmo a clássica mantiveram uma relação bem diferente para com aquilo que era denominado como alogia, hýbris, mania (as três formas de exterioridade à cultura clássica que Foucault cita em seu primeiro prefácio). No primeiro capítulo de Da clausura do fora ao fora da clausura, Pelbart mostra como em determinados momentos, mesmo Platão (no Fedro, especialmente) teria divinizado episódios onde o pensamento escapava a si mesmo; da mesma maneira, a palavra oracular era considerada uma forma de sabedoria irredutível àquela dos filósofos. A partir disso mostra-se como na antiguidade havia uma relação de proximidade e distância que permitia comunicação com essas formas de exterioridade. Não há qualquer indicador de que gregos consideravam o pensamento desarrazoado como um outro eu. Assim, ele conclui que "se é verdade que a Antiguidade grega manteve com o louco uma proximidade de fato e uma distância absoluta de direito, contrariamente à época moderna, em que a identidade é de direito e a distância é de fato, através da reclusão asilar, o mínimo que podemos dizer, a respeito dessa inversão, é que com ela alterou-se a geografia da loucura" (PELBART, 2009, p.41).
}

Foucault e Blanchot: um diálogo possível a partir da ausência de obra e do esquecimento - Daniel Verginelli Galantin 


\begin{abstract}
se a razão, este pensamento que é poder, exclui a loucura como a própria impossibilidade; será que lá onde o pensamento busca colocar-se à prova [s'éprouver] mais essencialmente enquanto um poder sem poder, o qual visa recolocar em questão a afirmação que o identifica somente à possibilidade, ele não deveria de algum modo sair de si mesmo e passar do trabalho mediador e paciente para uma pesquisa errante, sem trabalho e sem paciência, sem resultado e sem obra? (BLANCHOT, 2009, pp.296-297).
\end{abstract}

Mesmo se os trabalhos posteriores de Foucault concentram-se na caracterização dos mecanismos históricos de poder-saber (elementos cuja articulação será constituinte dos objetos loucura, crime, sexualidade, assim como das formas de subjetividade que lhes correspondem), consideramos que a questão do estabelecimento de uma relação diferente com estes mecanismos, com os sujeitos e os objetos que lhes correspondem, e, em consequência, a questão acerca de como estabelecer uma relação outra para conosco mesmos, continuaria sendo primordial no pensamento foucaultiano. Ao mesmo tempo, a interrogação do pensamento foucaultiano sobre si mesmo será retomada em conferências, aulas, artigos e entrevistas a partir dos temas dos limites, da crítica e da relação entre ambos.

Ainda que datado, sustentamos que parte do artigo de Blanchot mantém-se válido devido à questão do papel das artes e a de um pensamento que se coloca à prova ao estabelecer uma relação diferente com a impossibilidade, assim como pelo desenvolvimento conceitual do tema da ausência de obra. Colocando lado-a-lado uma reflexão sobre o esquecimento e outra sobre História da loucura, o artigo propõe uma interpretação simultânea a um diálogo, onde o vínculo entre ausência de obra e inoperância é sublinhado e desenvolvido através do tema do esquecimento e de sua possível relação com o próprio pensamento de Foucault. Essas três noções remetem à interrupção, aos limites exteriores e ao deslizamento para fora da possibilidade, e se é verdade que o pensamento foucaultiano compartilha este espaço com aquele da loucura onde a obra se arruína, espaço que obriga o mundo a interrogar-se, então parece que ele trabalha em conformidade com o esquecimento mencionado por Blanchot. Se isto for assim, então mesmo um pensamento filosófico que se apoie numa vasta documentação histórica poderia trabalhar de modo a visar o esquecimento, no seguinte sentido: ao mostrar ou lembrar como determinados gestos esquecidos definiram aquilo que uma cultura considerou como seu exterior, e como, posteriormente, através de outros gestos, esse exterior foi internalizado enquanto o elemento que essa cultura reconhece como sendo a verdade dela, tudo isto constituiria um passo decisivo a fim de poder esquecer ativamente destes gestos e dessa cultura. Isso faz sentido na medida em que a pesquisa de arquivista é feita justamente porque esse passado participa de alguma maneira do presente, definindo-o positiva ou negativamente, e tanto mais ainda se esse trabalho

Foucault e Blanchot: um diálogo possível a partir da ausência de obra e do esquecimento - Daniel Verginelli Galantin 
coloca o presente diante de uma prova que não o identifica somente à possibilidade, isto é, se ele não traça limites que seriam intransponíveis para o pensamento ou pela ação moral e se ele tampouco almeja justificar o presente a partir de uma teleologia. Se já nesta época Foucault dizia em várias ocasiões que a via filosófica que lhe interessava era aquela do diagnóstico do presente (FOUCAULT, 2001a, p.553; 609; 634; 640-641; $693)^{7}$, é preciso dizer, seguindo a leitura de Javier De La Higuera, que este diagnóstico é sempre diferencial, pois trabalha para a interrupção deste presente, bem como se instala no espaço da interrupção já instaurada por outros pensamentos, de modo a dar lugar a um presente outro (DE LA HIGUERA, 2003, pp.XLIV-LI).

\section{Uma relação gemelar entre loucura e literatura: ausência de obra.}

Foucault atrela loucura e ausência de obra a partir de uma experiência moderna da linguagem, na medida em que esta não está mais regida pelo plano da representação. Em um artigo nomeado "A loucura, ausência de obra", publicado em maio de 1964, o filósofo deixará explícito o parentesco entre loucura e literatura que ficara apenas entrevisto no final de sua tese doutoral. Após iniciar com uma hipótese acerca do fim iminente do regime do círculo antropológico, Foucault dirá que Freud deve ser lembrado como aquele que colocou a loucura como uma experiência específica da linguagem, na qual não se trata de pensá-la a partir de um sentido oculto finalmente revelado (como afirmam as leituras psicologizantes de seus trabalhos), mas sim como uma linguagem cujo referente é essa própria linguagem, que não fala nada além de sua própria língua, e cuja chave de interpretação é dada por ela mesma: "linguagem esotérica, se quisermos, pois ela detém sua língua no interior de uma fala que, finalmente, não diz nada além desta implicação" (FOUCAULT, 2001a, p.445).

Assim, a loucura pode ser dita ausência de obra na medida em que sua linguagem situa-se nesta região vazia de auto-implicação onde nenhum sentido é estabelecido de antemão, mas que é como uma reserva de sentido. Tal reserva, porém, não deve ser entendida como uma provisão, mas como um espaço vazio a partir do qual é possível uma multiplicidade indeterminada de sentidos:

trata-se de uma figura que retém e suspende o sentido, arranja um vazio onde é proposta tão somente a possibilidade ainda não realizada que um tal sentido venha aí alojar-se, ou um outro, ou ainda um terceiro, e isso talvez até o infinito. A loucura abre uma reserva lacunar que designa e faz ver esse vazio onde língua e fala implicam-se, formam-se uma a partir

${ }^{7}$ Textos n. 42; 47; 50; 55 .

Foucault e Blanchot: um diálogo possível a partir da ausência de obra e do esquecimento - Daniel Verginelli Galantin 
da outra e não dizem nada além de sua relação ainda muda. Desde Freud a loucura ocidental tornou-se uma não-linguagem, pois ela tornou-se uma linguagem dupla (língua que existe apenas nesta fala, fala que não diz nada além de sua língua) -, ou seja, uma matriz da linguagem que, num sentido estrito, não diz nada. Dobra do falado que é uma ausência de obra (FOUCAULT, 2001a, p.446).

Pensar um vazio de sentido ou a suspensão do sentido da linguagem enquanto espaço vazio a partir do qual múltiplos sentidos podem vir a instalar-se nela fez com que Foucault situasse a literatura moderna neste espaço compartilhado com a loucura. Pois toda a literatura, a partir do final do século XIX (com a figura mais significativa de Mallarmé), caracteriza-se por tentar aproximar-se cada vez mais desta região de suspensão de sentido, espaço da ausência de obra que coincide com a loucura. Desta maneira, o parentesco entre literatura moderna e loucura não é estabelecido no plano psicológico, mas a partir de uma experiência da linguagem onde, deixando de ordenar-se pela representação das coisas, ela se sobrepõe somente a si mesma sem nada dizer: "ela designa a forma vazia de onde vem esta obra, quer dizer, o lugar de onde ela não cessa de estar ausente, no qual jamais a encontraremos porque ela nunca se encontrou aí" (FOUCAULT, 2001a, p.447). Isso quer dizer que o ser da linguagem na literatura moderna, assim como a linguagem da loucura, poderia ser definido "sem dúvida como algo que tem de se haver com a auto-implicação, com o duplo e com o vazio que se escava nele. Neste sentido, o ser da literatura, tal como ele se produz desde Mallarmé e vindo até nós, ganha a região onde, desde Freud, se faz a experiência da loucura" (FOUCAULT, 2001a, p.447). Trata-se daquilo que, ao analisar os interditos de linguagem, Foucault nomeou como uma palavra transgressiva, não medida em que ela seria um absolutamente outro, exterior à palavra reconhecida, mas sim na medida em que forma um duplo que desdobra a palavra reconhecida em algo outro - movimento de desdobra do mesmo em algo outro. Logo, trata-se de uma palavra que

submete uma fala aparentemente conforme ao código reconhecido a um outro código cuja chave é dada nesta mesma fala; de modo que esta é desdobrada no interior de si mesma: ela diz aquilo que ela diz, mas ela acrescenta um excedente mudo que enuncia silenciosamente aquilo que ela diz e o código segundo o qual ela diz. Não se trata de uma linguagem cifrada, mas de uma linguagem estruturalmente esotérica. Isso significa que ela não comunica uma significação interdita ao escondê-la; ela se instala de início numa redobra essencial da palavra (FOUCAULT, 2001a, p.444).

Com isso não estaria Foucault encerrado na análise do isomorfismo entre loucura e literatura moderna, estabelecido a partir de uma experiência comum da linguagem que o levaria a uma espécie de ontologia negativa,

Foucault e Blanchot: um diálogo possível a partir da ausência de obra e do esquecimento - Daniel Verginelli Galantin 
tomando emprestado certas noções da linguística e da reflexão blanchotiana? O que teria restado em suas reflexões posteriores daquele sentido ético-político da noção de ausência de obra, tal como ela aparecia ao final de História da loucura? Primeiramente, ao que tudo indica, este texto pode ser lido como uma espécie de esclarecimento complementar acerca da noção de ausência de obra, noção que aparece sub-repticiamente ao final da tese de Foucault. Ou seja, nada do que foi dito nas últimas páginas da tese parece ter sido alterado neste escrito posterior, o qual traria consigo principalmente acréscimos e esclarecimentos.

Em segundo lugar, é preciso dizer que mesmo em meio a toda densidade teórica deste texto focado na linguagem, Foucault dirá que a literatura moderna "supunha sob cada uma de sua frases, sob cada uma de suas palavras, o poder de modificar soberanamente os valores e as significações da língua à qual, apesar de tudo (e de fato), ela pertencia; ela suspendia o reino da língua num gesto atual de escritura" (FOUCAULT, 2001a, pp.446-447). Mudar os valores e as significações de uma língua parece acarretar transformações ético-políticas, ao menos na medida em que o modo como nos relacionamos conosco mesmos e com os outros passa também pela linguagem, uma linguagem que veicula valores com seus adjetivos e que separa e identifica coisas com substantivos, por exemplo. $\mathrm{Na}$ medida em que um gesto de escritura utiliza-se da língua cotidiana e a desdobra num espaço literário que forma um duplo do mundo cotidiano, muitas vezes absurdo e inteligível, como em Kafka ou Beckett, a evidência deste mundo organizado por esta linguagem acaba fragilizada.

Se parte do pensamento político considera fundamental uma estrutura dialógica de troca linguística para a mediação de conflitos e o estabelecimento de consensos, a reflexão de Foucault nos faz indagar que tipo de política vincular-se-ia a tal linguagem que é como uma moeda que resiste à troca ou que, imitando a moeda corrente, veicula um valor irreconhecível e que interrompe a circulação da linguagem a partir de um desdobramento dela mesma ${ }^{8}$. Ao mesmo tempo é preciso dizer que, para Foucault, de acordo com o que vimos nos momentos finais de História da loucura, a ruptura de sentido organizada pela linguagem daqueles que uma vez enlouqueceram afeta o mundo organizado pelo círculo antropológico, impondo uma "questão sem reposta", ou seja, rompendo o sentido deste mundo organizado desta maneira, o que inclui também suas instituições. Logo, tal ruptura de sentido apresenta um viés político.

\footnotetext{
${ }^{8}$ Pensamos que este movimento de alteração na linguagem poderia ser colocado em paralelo à parresía cínica estudada em $A$ coragem da verdade. Trata-se do movimento de transvaloração dos quatro valores da verdade da cultura grega clássica e do período imperial operada pelo cinismo antigo. A diferença, neste caso, seria que tratar-se-ia não apenas de uma linguagem, mas de uma vida transgressiva. Sobre isso ver as aulas de 7 e 14 de março de 1984 (FOUCAULT, 2009).
}

Foucault e Blanchot: um diálogo possível a partir da ausência de obra e do esquecimento - Daniel Verginelli Galantin 
Na quarta e última de uma série de emissões feitas por Foucault em 1963 na Radio France, Foucault explora de modo direto e explícito o sentido político deste parentesco entre loucura e literatura. Ao colocar as possibilidades de falar e de enlouquecer como vizinhas, a loucura é tida como "a mais perigosa, mas talvez também a mais maravilhosa ou a mais insistente de nossas liberdades" (FOUCAULT, 2013, p.52). Foucault se utiliza de um artifício para nos convidar a imaginar um mundo onde todos fossem sãos, para dizer que mesmo aí a loucura seria possível através da linguagem. Através da linguagem continuaria sendo possível "confundir seu sentido mais familiar e, através de um único e miraculoso jorro de algumas palavras, colocar o mundo pelo avesso" (FOUCAULT, 2013, p.52). Isso significa que mesmo num mundo hipotético sem loucura ainda seria possível que a linguagem se desdobrasse sobre si mesma, constituindo aquilo que foi definido como uma fala esotérica ou como palavra transgressiva. Todo homem que fala se utiliza, mesmo que secretamente, da liberdade de ser louco, assim como todo louco que fala e que parece tornarse estrangeiro à linguagem dos homens sãos também é "prisioneiro do universo fechado da linguagem" (FOUCAULT, 2013, p.52).

Mas qual seria o motivo de tamanho interesse pela linguagem da loucura em nossa sociedade, ao menos como o entende Foucault? O motivo seria eminentemente ético-político: a ruína de todos os ideais políticos que colocaram a possibilidade de absoluta desalienação humana, questão que caminha ao lado da impossibilidade do estabelecimento de um fundamento moral que se coloque como princípio normativo absoluto para a ação humana ou para a relação consigo e com os outros. Encontra-se aqui, no pensamento de Foucault, a questão de fundo nietzschiano que coloca a modernidade como momento de consumação da morte de Deus, o que significa também o fim das versões laicizadas da realização de um homem total que tomaria o lugar de Deus ${ }^{9}$. A História perde a unidade de seu sentido e desfaz-se o lugar mesmo do Sujeito que supostamente a guiava até então. Ao mesmo tempo, as instituições que tomam esta figura do homem desalienado como modelo ideal ou real para sua atividade perdem seu sentido, restando apenas seu viés de controle social. Mas talvez seja justamente a partir deste esvaziamento dos céus que podemos recolocar a ética e a política a partir de outros termos, num movimento de desdobra da linguagem cotidiana numa linguagem outra, mudando com isso seus valores. Embora a declaração de Foucault quanto a tal possibilidade seja breve e ao mesmo tempo generalizante demais, sua aposta parece seguir na direção da linguagem como possível eixo de repolitização, visto que tornarse louco constituir-se-ia enquanto uma forma de liberdade:

\footnotetext{
9 Para um aprofundamento deste tema, veja-se o artigo Além do homem e homem total (LEBRUN, 2006, pp.169-198).
}

Foucault e Blanchot: um diálogo possível a partir da ausência de obra e do esquecimento - Daniel Verginelli Galantin 
Eu acredito que poderíamos dizer que, no fundo, nós não acreditamos mais na liberdade política, assim como o sonho, o famoso sonho de um homem desalienado caiu agora em derrisão. De tantas quimeras, o que nos restou? Pois bem, as cinzas de algumas palavras. E nosso possível, nós homens de hoje não o confiamos mais às coisas, aos homens, à História, às instituições; nós o confiamos aos signos.

(...)

Num mundo onde Deus está definitivamente morto, e onde, apesar de todas as promessas da direita e da esquerda, sabemos que não seremos felizes, a linguagem é nosso único recurso, nossa única fonte. Aquilo que ela nos revela, no vazio mesmo de nossa memória e sob cada uma dessas palavras que galopam através de nossas cabeças, é a maravilhosa liberdade de ser louco. Talvez seja por isso que a experiência da loucura é singularmente aguda em nossa sociedade, e que ela forma de algum modo o limite silvano de nossa literatura (FOUCAULT, 2013, p.54).

Mas sobre este ponto é preciso ressaltar que Foucault de modo algum diz que nossa liberdade estaria em termos delírios de perseguição, escutarmos vozes ou termos surtos psicóticos. Tal liberdade do enlouquecer diz respeito ao poder de transformação historicamente inerente $d a$ e $n a$ linguagem, espaço constituído a partir do momento em que ela abandona o reino da representação e passa a adquirir um caráter eminentemente ficcional no sentido mais radical do termo, o que significa que ela produz, que ela cria: "As palavras, seu encontro arbitrário, sua confusão, todas as suas transformações protoplasmáticas, são por si mesmas suficientes para fazer nascer um mundo simultaneamente verdadeiro e fantástico (...)" (FOUCAULT, 2013, p.56). Estamos diante de uma reflexão muito próxima daquela de Blanchot sobre a experiência de Mallarmé, para quem a linguagem poética é um tipo de linguagem que não designa uma coisa e nem dá voz a uma pessoa, mas que se fala. Disso Blanchot aponta que as palavras têm um poder de fazer desaparecer as coisas, mas também de fazer desaparecer elas mesmas naquilo que elas realizam ${ }^{10}$ (BLANCHOT, 2014, p.45). Todo o esforço de Mallarmé seria o de aproximar-se desse ponto:

Quanto mais sentido e ambição toma a Obra, retendo nela não apenas todas as obras, mas todas as formas e poderes do discurso, tanto mais a ausência de obra [absence d'oeuvre] parece propor-se, sem, contudo, deixar-se designar. Isso se passa com Mallarmé. Com Mallarmé a Obra toma consciência de si mesma e, com isso, apreende-se como aquilo que

\footnotetext{
${ }^{10}$ Há toda uma prolongada reflexão blanchotiana em torno ao tema de uma figura da negação que seria diferente da negação determinada hegeliana, a qual faz da afirmação sempre o resultado da dupla negação. Blanchot vincula a ausência de obra a uma negação simultaneamente positiva, temática que parece inserir-se no contexto da recepção da filosofia nietzschiana na França dos anos 50 e 60.
}

Foucault e Blanchot: um diálogo possível a partir da ausência de obra e do esquecimento - Daniel Verginelli Galantin 
coincidiria com a ausência de obra - esta última desviando para sempre a obra da coincidência para consigo mesma e destinando-a à impossibilidade. Movimento de desvio [détour] onde a obra desaparece na ausência de obra, mas onde a ausência de obra sempre escapa reduzindo-se a ser somente a Obra sempre desaparecida $^{11}$ (BLANCHOT, 2009, p.622).

A partir de tais reflexões, podemos dizer que não estamos diante de uma exígua liberdade da linguagem, pois na medida em que confiamos nosso possível aos signos, sempre será possível deslizá-los rumo a esta região vazia de ruptura de sentido (a ausência de obra), a partir da qual uma multiplicidade indeterminada de sentidos serão possíveis - logo, aí há "lugar" mesmo para o impossível. A profunda coerção vinculada à linguagem e suas estruturas é inseparável da liberdade que há na possibilidade de desdobramento da linguagem cotidiana que serve para fins de comunicação (assim como uma moeda serve para estabelecer equivalência entre coisas distintas) numa linguagem outra, e, com isso, mudar os valores que ela veicula; ocorre apenas que o mesmo movimento se passa também na linguagem enlouquecida. Assim, suspender o reino da língua num gesto de escritura adquire um valor de transformação éticopolítica e tais elementos indicam que esse é o mesmo espaço da escrita da tese de Foucault, o espaço da beira do abismo inoperante:

A Obra onde rege a ausência de obra conduz até à loucura aquele que não se chama mais Mallarmé: se possível, entendamos este até [jusqu'à em itálico no original] como o limite que, ultrapassado, seria a loucura decidida; donde seria preciso concluir que o limite - 'a beira da loucura' - considerado como indecisão que não se decide, ou ainda como não-loucura, é mais essencialmente louco: seria abismo, não o abismo, mas a beira do abismo (BLANCHOT, 2009, p.628).

\section{Posteridades de um diálogo: atitude crítica e esquecimento ativo do presente e de si mesmo}

Propomos que a continuidade do diálogo de Foucault com Blanchot tomaria a forma da apropriação de alguns elementos do pensamento deste último, os quais ainda repercutiriam no pensamento tardio de Foucault. Tal apropriação, no entanto, acompanharia os deslocamentos do próprio pensamento foucaulitano, de modo que se há uma continuidade deste diálogo com Blanchot, isto se dá porque o próprio pensamento de Foucault

\footnotetext{
${ }^{11}$ Tudo indica que este trecho do livro publicado em 1969 foi escrito em 1958. Nossa fonte é o artigo de JohnMcKeane, intitulado L'absence de livre à venir, o qual consta no Espace Maurice Blanchot: <http://www.blanchot.fr/fr/index.php?option=com_content\&task=view\&id=246\&Itemid=4 0\#_ftn2>, acessado em 29 de novembro de 2015.
}

Foucault e Blanchot: um diálogo possível a partir da ausência de obra e do esquecimento - Daniel Verginelli Galantin 
se transforma. Assim, concluímos este artigo indicando alguns pontos e aspectos em que este diálogo contínuo com Blanchot poderia ser identificado, assim como sugerindo a peculiaridade desta apropriação, que, enquanto tal, transforma aquilo que é apropriado.

O conjunto de questionamentos sobre o diagnóstico do presente, sobre a transformação possível deste e sobre a figura dos limites é abordado durante diferentes momentos do pensamento de Foucault. Nesta conclusão destacaremos seu artigo mais tardio, publicado em 1984, onde, juntamente com o texto de Kant sobre o esclarecimento e o de Baudelaire sobre a modernidade, Foucault proporá que se considere esta última enquanto um êthos atrelado à crítica. No entanto, ao invés de pensar a atividade crítica a partir do estabelecimento de limites intransponíveis e legitimadores para o livre uso das faculdades, Foucault a pensará enquanto modo de desarticulação de universais, como processo que mostra aquilo que neles há de singular, visto que são resultado de coerções arbitrárias. Na primeira aula de $O$ governo de si e dos outros, de 1983, Foucault mostrara como em Resposta à pergunta: Que é Esclarecimento? Kant teria apontado a necessidade da ilustração subordinar-se à Crítica - trata-se aqui das três Críticas escritas por Kant -, a qual estabeleceria os limites dentro dos quais poder-se-ia fazer um livre uso público e autônomo das faculdades, ou seja, sem a direção de outrem (FOUCAULT, 2010d, pp.29-32). Porém, o texto do ano seguinte nos mostra como esta dívida para com Kant é muito parcial, estando atrelada principalmente à interrogação pelo presente, ou seja, nos termos da via filosófica de uma ontologia do presente, aberta por Kant. Desta maneira, tal dívida deve ser pensada conjuntamente a uma forte dissidência, visto que Foucault inverterá o esquema kantiano ao fazer com que a crítica (pensada antes como uma atitude do que como uma reflexão transcendental) dependa da ilustração, o que significa fazer com que a interrogação sobre a verdade torne-se subordinada à interrogação pelo presente (DE LA HIGUERA, 2009, p.XXXIX).

Com esta transformação operada por Foucault, a crítica pensada enquanto "ontologia crítica de nós-mesmos" ou "ontologia histórica de nósmesmos" (FOUCAULT, 2001b, pp.1393-1394) deixa de ser concebida como estabelecimento de limites necessários e intransponíveis, para se compreender e se exercer enquanto esforço de localização dos limites históricos daquilo que, no presente, é considerado como universal ou necessário. A partir desta transformação, a ontologia crítica de nós-mesmos aponta para a ultrapassagem possível dos limites tidos como intransponíveis e necessários: "Em suma, trata-se de transformar a crítica exercida sob a forma de limitação necessária em uma crítica prática sob a forma do ultrapassamento [franchissement] possível" (FOUCAULT, 2001b, p.1393). Ao mostrar como diferentes períodos estabeleciam os limites daquilo que se pode pensar, do que é enunciado como verdadeiro, quais relações de poder permeiam os discursos verdadeiros, assim como as maneiras pelas quais os

Foucault e Blanchot: um diálogo possível a partir da ausência de obra e do esquecimento - Daniel Verginelli Galantin 
sujeitos são levados a se constituírem como sujeitos éticos a partir de diferentes trabalhos exercidos sobre si mesmos, a ontologia do presente mostra os limites de tais épocas, os quais muitas vezes ainda nos dizem respeito; ao mesmo tempo, também trata-se de fazer ver o caráter histórico e contingente de tais limites. Os diferentes momentos delimitados também não são encadeados por uma única corrente lógica de continuidade ou de relação causa-consequência, mas através de múltiplos fios de acontecimentos históricos. Quando a análise chega ao presente podemos ver todo seu potencial de desestabilização de identidades, de sujeitos e objetos que eram antes considerados como permanentes ao longo da história. Como os próprios limites do presente também serão traçados a partir de acontecimentos históricos, isso faz com que, além de perdermos a sensação de empatia com nosso passado, também percamos nossa empatia para conosco mesmos.

Para ilustrar este movimento podemos fazer um jogo gramatical ao estabelecer que nosso passado passar a ser o passado deles, daqueles que viveram a partir de tais modos de pensar, agir, relacionar-se consigo. De modo que o passado perde o viés que fazia dele aquilo que estabelece e justifica a identidade do presente, para então mostrar que ambos seriam singularidades acontecimentais. Ao mesmo tempo, nosso próprio presente também deve passar a ser o presente deles, o que acontece apenas na medida em que deixamos de ser nós-mesmos. Em suma, localizar os limites daquilo que o presente considera como universal implica delimitar este presente a partir da historicização de seus limites. Tal esforço crítico, ao mesmo tempo em que pensa o ser desses limites não a partir de uma ontologia formal ou de uma reflexão transcendental, mas sim como resultado de acontecimentos históricos, abre espaço para o advento de um presente outro, o qual pode ser vislumbrado como possível quando se mostra que tais limites considerados necessários, são na realidade atravessáveis.

Parte do pensamento blanchotiano ajudaria a colocar tal espaço de atravessamento possível de limites para um presente outro, o qual apresentamos acima a partir de um deslocamento pronominal, como um movimento onde o presente desvia de si mesmo, ou ainda, quando se esquece ativamente de si mesmo. Desta maneira, na medida em que o diagnóstico crítico fabrica um desvio em relação ao presente, assim como aproveita-se do desvio que outros pensamentos já instauraram ${ }^{12}$, ele não visa encontrar estruturas universais do conhecimento ou da ação moral, mas sim abordar os discursos que perpassam nossas maneiras de pensar e de agir enquanto acontecimentos históricos. Mostrando que a constituição de nosso

\footnotetext{
12 Podemos dizer que, para Foucault, a atividade crítica não se restringe à filosofia institucionalizada na Universidade. Sinal disso é que junto a Kant encontramos Baudelaire no texto de 1984. Foucault também reconheceu o potencial crítico e desestabilizador tanto da literatura quanto da etnologia estrutural, da linguística e dos estudos de mitologia comparada de Dumézil, por exemplo.
}

Foucault e Blanchot: um diálogo possível a partir da ausência de obra e do esquecimento - Daniel Verginelli Galantin 
ser é histórica, ou seja, mostrando que nós-mesmos somos acontecimentos históricos, a ontologia crítica não nos mostra aquilo que nos seria impossível de nos tornarmos, mas, posto que ela trata "da contingência que nos fez ser aquilo que nós somos, ela desbloqueará a possibilidade de não mais ser, fazer ou pensar isso que nós somos, pensamos ou fazemos" (FOUCAULT, 2001b, p.1393). Com isso, aquele que se engaja na atitudelimite torna-se, ele também, outro; tal processo de transformação de si ainda poderia ser descrito enquanto um esquecimento ativo de si mesmo, na medida em que é resultado de um trabalho operado sobre si mesmo.

Isso significa que a atitude-limite elimina do presente e do passado todos os seus caracteres de necessidade ou de inserção numa história universal da razão, rompe as identidades dos sujeitos e objetos que percorreriam a história como rostos verdadeiros ou essências escondidas atrás de máscaras, para então mostrar um grande baile de máscaras por detrás das quais existem apenas outras máscaras. Este é um viés do pensamento foucaultiano que remete a um momento muito anterior a 1984. Já em seu principal escrito publicado sobre Nietzsche, Foucault mencionava que a pesquisa pelo sentido histórico deveria afastar-se de toda filosofia da história e de todo elemento supra-histórico, o que implicava pensar em três usos da história. Estes três usos, encontrados em aforismos da década de 1880, seriam como que desdobramentos que pervertem os três primeiros tipos de história abordados e criticados por Nietzsche na II Consideração intempestiva, de maneira que abririam, assim, a possibilidade de uma história voltada para uma contra-memória, ou, ainda, para o esquecimento:

Um é o uso paródico e destruidor da realidade, o qual se opõe ao tema da história-reminiscência ou reconhecimento; outro é o uso dissociativo e destruidor da identidade, o qual se opõe à história-continuidade ou tradição; o terceiro é o uso sacrificial e destruidor da verdade, o qual se opõe à históriaconhecimento. De toda maneira, trata-se de fazer da história um uso que a libere para sempre do modelo, simultaneamente metafísico e antropológico, da memória. Trata-se de fazer da história uma contra-memória e, consequentemente, nela desdobrar toda uma outra forma do tempo (FOUCAULT, 2001b, pp.1020-1021).

A possibilidade de tal uso da história como contra-memória, ou ainda, como um uso voltado para o esquecimento, parece ser retomada no escrito de 1984 quando Foucault apresenta um sentido de crítica multifacetado, do qual uma das facetas parece coadunar-se com o esquecimento mencionado por Blanchot já em 1961. A possibilidade de não mais ser o que se é ou de pensar como se pensa pode muito bem ser considerada como a possibilidade de desviar-se ativamente de si mesmo e do presente onde se está situado. Talvez a maior diferença seja que, neste escrito tardio, Foucault pensa a crítica como análise histórica das práticas de

Foucault e Blanchot: um diálogo possível a partir da ausência de obra e do esquecimento - Daniel Verginelli Galantin 
condução de condutas dos outros, de produção de saberes e de condução de si-mesmo. Neste sentido, estamos diante de todo o esforço de trabalho em arquivos, da reflexão sobre a analítica do poder e da governamentalidade, assim como da genealogia da constituição ética dos sujeitos. Já em Blanchot estamos diante de outro registro de reflexão, marcado pela escrita fragmentária, por um conjunto de reflexões sobre poesia, linguagem e literatura, um enfrentamento direto e conceitual com o hegelianismo, e toda uma reflexão sobre ética e política que permeia tal caminho.

No entanto, se é certo que estamos diante de registros diferentes de pensamento, do mesmo modo como também há importantes deslocamentos teóricos entre períodos distintos do pensamento foucaultiano, isso não significa que não hajam conexões entre momentos distintos do pensamento de Foucault assim como entre Foucault e Blanchot. Ao que tudo indica, durante os escritos da década de 1960 são as reflexões centradas na linguagem que trazem o diálogo com Blanchot a partir da figura do esquecimento ou desvio, pensados como ausência de obra - por isso podemos encontrar o uso direto de um tema blanchotiano (a inoperância) neste período. As reflexões sobre o espaço da linguagem moderna evidentemente vinculam-se a questionamentos ético-políticos, os quais são pensados a partir do tema nietzschiano da morte de Deus e em menor grau sobre o niilismo, assim como a partir da recepção francesa do pensamento nietzschiano durante as décadas de 1950 e 1960. Já durante a década de 1970 o diálogo com Blanchot seria possível a partir do aprofundamento das reflexões de Foucault sobre a história (iniciadas já na década anterior ${ }^{13} \mathrm{com}$ seu contato com a École des annales) e com seu interesse pelo viés genealógico do pensamento nietzschiano - e não tanto pelo par morte de Deus e niilismo. Trata-se, então, de pensar uma história que seja voltada para o esquecimento devido a seu potencial de desestabilização da identidade de sujeitos, objetos, assim como da própria verdade. No contexto do escrito tardio de Foucault, durante a década de 1980, a atitude-limite é considerada enquanto uma interrogação pelos limites do presente (recolocando a questão do diagnóstico, pensada já na década de 1960), o qual tem como seu espaço e como seu resultado fabricar um desvio com relação ao presente. Tal desvio, segundo Blanchot, vem do esquecimento e, para Foucault, pode ser pensado como possibilidade de transformação de nossa relação para conosco, com os outros, com as relações de poder que nos transpassam e os saberes que elas incitam. Logo, podemos afirmar que a crítica tem como efeito ético que nos esqueçamos ativamente de nósmesmos. Ou seja, a figura do esquecimento ganha uma dimensão ética acentuada a partir de então, uma ética pensada a partir do trabalho que se

\footnotetext{
${ }^{13}$ Veja-se, porexemplo, a entrevista de 1967: Sur les façons d'écrire l'histoire (FOUCAULT, 2001a, p.613).
}

Foucault e Blanchot: um diálogo possível a partir da ausência de obra e do esquecimento - Daniel Verginelli Galantin 
exerce sobre si mesmo e não como prescrição de conteúdos ou formas normativas.

Toda esta transversalidade a partir da qual podemos ler o último escrito de Foucault sobre o Esclarecimento nos leva a indagar se não estaríamos diante de uma espécie de viés inoperante da crítica foucaultiana. Tal caracterização, além de ajudar a compreender a ausência de normatividade fundacional em seu pensamento, tanto no plano ético quanto político e epistemológico, também auxiliaria a compreender os desvios próprios do pensamento foucaultiano, tanto com relação à forma quanto ao conteúdo - desvios que impedem que coloquemos sua obra sob o signo da Obra de que fala Blanchot. Não se trata de atribuir unicamente ao viés inoperante a razão maior dos deslocamentos no pensamento de Foucault. As transformações conceituais, mudanças de recorte histórico, localização de novas formas de poder, são igualmente importantes para a compreensão de tais deslocamentos. Porém, tal viés inoperante serve ainda, por um lado, como arma de combate a todo esforço de sistematização normativa do pensamento foucaultiano, assim como, por outro lado, responde às críticas por sua ausência de normatividade. Na verdade, é nesta falta que estaria boa parte de sua força e de sua singularidade ${ }^{14}$.

$\mathrm{Na}$ medida em que a crítica implica uma transformação de si-mesmo para a qual não há qualquer possibilidade de extrair estruturas transcendentais do si-mesmo, vemos que Foucault prece situar sua própria escritura em tal espaço crítico inoperante quando se depara com os desvios de seu trabalho - o que significa dizer que aquele que diagnostica está implicado no ato de pensamento crítico, não estando numa posição transcendente de julgamento. Tal consideração também pode ajudar, em parte, a compreender as mudanças de estilo na escrita de Foucault, desde a escrita rebuscada e com tons proféticos de História da loucura, passando pela minuciosidade analítica de Vigiar e punir, até a escrita sóbria de $O$ uso dos prazeres e $O$ cuidado de $s i^{15}$. Tais mudanças, além de atrelarem-se aos deslocamentos teóricos de Foucault, fariam parte de uma escrita onde aquele

\footnotetext{
${ }^{14}$ Sobre a questão da normatividade no pensamento foucaultiano, veja-se também o artigo de Judith Butler What is critique? An essay on Foucault's virtue (BUTLER, 2013). Artigo original também pode ser acessado em <http://eipcp.net/transversal/0806/butler/en> no dia 19/12/2015. A partir da conferência de 1978 Que'est-ce que la critique? (FOUCAULT, 2015), Butler aponta para um sentido de crítica vinculado à noção de virtude. Ao invés de fundar uma normatividade, esta crítica aponta como, mesmo dentro de um campo de normatividade social do qual nunca se pode estar fora, sujeitos podem colocar em jogo tais normas num processo de estilização de sua existência: "Para Foucault, ganhar uma distância crítica perante a autoridade estabelecida não significa apenas reconhecer os modos como os efeitos coercitivos do conhecimento manifestam-se na formação do próprio sujeito. Significa, também, por em risco nossa própria formação enquanto sujeitos" (BUTLER, 2013, p.176).

${ }^{15}$ Sobre isso, ver o artigo de Duarte e César, "Foucault e o pensamento-escritura como experiência transformadora", no prelo.
}

Foucault e Blanchot: um diálogo possível a partir da ausência de obra e do esquecimento - Daniel Verginelli Galantin 
que escreve também é obrigado a deslocar-se, a desviar-se de si mesmo, logo, a esquecer de si mesmo.

Semelhante esforço para transformação ou esquecimento de si mesmo pode ser encontrado em outros textos importantes, como o prefácio de $O$ uso dos prazeres, quando Foucault dirá que a curiosidade que o levou aos antigos é daquele tipo que, ao invés de assimilar conhecimentos, permite "desprender-se de si mesmo" [se dépendre de soi-même] e constituir um saber que assegure o "descaminho" [égarement] daquele que conhece (FOUCAULT, 1984, pp.14-15). E tudo isso, novamente, não é retórica, mas engajamento necessário para aquele que considera a filosofia enquanto um "trabalho crítico do pensamento sobre si mesmo" (FOUCAULT, 1984, p.14), o qual está sempre vinculado a um modo de vida. Tal dimensão ética, no entanto, não deixa de estar vinculada um tipo de trabalho histórico que não é "de historiador", pois trata-se de um exercício onde "o trabalho de pensar sua própria história pode libertar o pensamento daquilo que ele pensa silenciosamente, e permitir-lhe pensar diferentemente" (FOUCAULT, 2010b, p.16). Ou seja, estamos diante de um trabalho onde, ao pensar sua própria história, o pensamento seria capaz de não mais pensar aquilo que se pensava, movimento de transformação que também poderia ser colocado sob a rubrica do esquecimento. Mais uma vez nos deparamos com uma íntima articulação entre esquecimento e história. Ao invés de mostrar uma cadeia lógica e teleológica do devir, ou de subordinar-se às condições $a$ priori da história, o pensamento que pensa sua própria história acaba por não pensar mais como se pensa, agir como se age, ter a mesma relação para consigo e para com os outros, ou para com as relações de poder que o atravessam. A permanência do mesmo tipo de injunção de esquecimento como elemento indissociável do pensamento pode ser encontrado quando o filósofo disser em 1977: "Meu modo de não ser mais o mesmo é por definição a parte mais singular disso que sou" (FOUCAULT, 2001b, p.784), afirmação que pode ser entendida como um modo de se esquecer ativamente de si mesmo.

Quanto a estas afirmações, apenas uma última consideração. Elas dizem respeito ao entendimento de Foucault quanto às transformações que seu trabalho deve operar nele mesmo, ou seja, trata-se de uma reflexão quanto à função etopoética ${ }^{16}$ de sua escrita e de sua pesquisa. Ao mesmo tempo, tal função etopoética não remete a um trabalho ético individualista ou solipsista, resultado da reclusão pura e do exercício contemplativo do

\footnotetext{
${ }^{16} \mathrm{~A}$ noção de etopoética diz respeito, no contexto da antiguidade, aos conhecimentos que eram capazes operar uma transformação no modo de ser daquele que passava a conhecer. Ou seja, não era a validade epistemológica que classificava um conhecimento enquanto útil e não ornamental, mas sim seu poder de transformar o ethos. Sobre isso ver a aula de $10 \mathrm{de}$ fevereiro de 1982 (FOUCAULT, 2010a). No prefácio de O uso dos prazeres, ela também é retomada (FOUCAULT, 2010c, p.20).
}

Foucault e Blanchot: um diálogo possível a partir da ausência de obra e do esquecimento - Daniel Verginelli Galantin 
pensamento ${ }^{17}$. Durante o final de 1978, na maior entrevista de todos os Dits et écrits, na qual Foucault faz diversas referências a Bataille e a Blanchot, ele diz escrever livros-experiência os quais transformam aquilo que ele pensa. No entanto, semelhante experiência não se restringe apenas ao plano pessoal: "A relação com a experiência deve, no livro, permitir uma transformação, uma metamorfose que não seja apenas minha; mas que possa ter um certo valor, um caráter acessível aos outros, que essa experiência possa ser feita pelos outros" (FOUCAULT, 2001b, p.865). Há uma dimensão eminentemente coletiva neste modo de não ser mais o mesmo ou de esquecer de si-mesmo: "(...) enfim, esta experiência deve até certo ponto poder ligar-se a uma prática coletiva, a um modo de pensar. É o que produziu-se, por exemplo, com um movimento como o da antipsiquiatria ou o movimento dos detentos na França" (FOUCAULT, 2001b, p.865). Ou seja, os livros-experiência caracterizam-se por comunicar não tanto um conjunto de verdades epistemologicamente verificáveis, mas sim um conjunto de transformações.

Assim, se a atitude-limite vinculada à ontologia crítica do presente apresenta como um de seus resultados o esquecimento de si-mesmo, há uma dimensão eminentemente coletiva neste esquecimento, o qual ainda poderia ser nomeado de dessubjetivação (FOUCAULT, 2001b, p.862). O si-mesmo a ser esquecido é tanto um ser individualizado quanto é resultado de um conjunto de modos de condução de condutas incorporados coletivamente em processos de assujeitamento. O próprio duplo sentido da palavra sujeito ressaltado por Foucault em 1982 aponta para isso: "sujeito submetido a outrem pelo controle e dependência, e sujeito vinculado à sua própria identidade pela consciência ou conhecimento de si" (FOUCAULT, 2001b, p.1046). Ainda no mesmo escrito, ao tratar das lutas políticas contemporâneas encontraremos em suas palavras traços deste movimento que tentamos colocar sob a rubrica do esquecimento:

sem dúvida o objetivo principal hoje não é o de descobrir, mas de recusar o que nós somos. É necessário imaginarmos e construir aquilo que poderíamos ser para nos desvencilharmos dessa espécie de 'dupla coação' política que é a individualização e a totalização simultâneas das estruturas do poder moderno (FOUCAULT, 2001, p.1051).

A necessidade de recusar ativamente tanto as formas de individualidade quanto de coletividade, ou ainda, de recusar determinados processos de subjetivação pode, sem grandes problemas, ser pensada como

\footnotetext{
${ }^{17}$ A própria divisão indivíduo-sociedade não é válida para a maioria das pesquisas foucaultianas. Um de seus mais importantes gestos é mostrar como determinadas formas de individualidade ou de coletividade são resultado de processos e não conceitos reguladores ou heurísticos para compreender o social. Por isso o pensamento de Foucault trabalha com noções como subjetivação, assujeitamento, individualização.
}

Foucault e Blanchot: um diálogo possível a partir da ausência de obra e do esquecimento - Daniel Verginelli Galantin 
um modo de esquecer ativamente de si mesmo. Tudo isso parece mostrar que, desde muito cedo, Foucault parece ter levado em conta a necessidade de esquecer ativamente de si mesmo e do presente como implicação ética do pensamento crítico, da atividade de diagnóstico do presente, e da própria escritura. Isto também significa que, muito embora o diálogo com Blanchot tenha passado por deslocamentos durante a obra foucaultiana, ainda assim ele não parece ter sido interrompido.

\section{Referências bibliográficas}

ARTIÈRES; BERT; POTTE-BONNEVILLE; REVEL. Présentation. IN: La grande étrangère: à propos de la littérature. Paris: Éditions EHESS, 2013. BLANCHOT, Maurice. L'Entretien infini. Paris: Gallimard, 2009. . L'Espace littéraire. Paris: Gallimard, 2014. . Michel Foucault tel que je l'imagine. Saint Clément de Rivière: Éditions Fata Morgana, 1986.

BUTLER, Judith. O que é a crítica ? Um ensaio sobre a virtude de Foucault. IN : Cadernos de Ética e Filosofia Política. N.22. DALAQUA, Gustavo Hessmann (trad). São Paulo : USP, 2013, pp.159-179.

. What is critique? An essay on Foucault's virtue. IN: EIPCP. <http://eipcp.net/transversal/0806/butler/en> acessado em novembro de 2015.

CESAR, M.R.A.; DUARTE, André. Foucault e o pensamento-escritura como experiência transformadora. No prelo.

DE LA HIGUERA, Javier. Estúdio Preliminar. IN: FOUCAULT, Michel. Sobre la Ilustración. DE LA HIGUERA, Javier (trad.). Madri: Tecnos, 2007.

FAVREAU, Jean-François. Vertiges de l'écriture: Michel Foucault et la littérature (1954-1970). Lyon: ENS Éditions, 2012.

FOUCAULT, Michel. A hermenêutica do sujeito. São Paulo: Martins Fontes, 2010a.

Dits et écrits. Tome I. Paris: Gallimard, 2001a.

Dits et écrits. Tome II. Paris: Gallimard, 2001b.

História da loucura. São Paulo: Perspectiva, 2012.

Janeiro: Graal, 2010b.

História da sexualidade: O cuidado de si. Rio de

Janeiro: Graal, 2010c.

História da sexualidade: O uso dos prazeres. Rio de .Histoire de la folie à l'âge classique. Paris: Gallimard, 1972.

Le courage de la vérité :le gouvernement de soi et des autres II. Paris: Éditions EHESS ; Gallimard; Seuil, 2009.

Éditions EHESS, 2013.

.La grande étrangère: à propos de la littérature. Paris:

Foucault e Blanchot: um diálogo possível a partir da ausência de obra e do esquecimento - Daniel Verginelli Galantin 
Gallimard; Seuil, 2008.

Le gouvernement de soi et des autres. Paris: EHESS; Fontes, 2010d.

O governo de si e dos outros. São Paulo: Martins

Paris: Vrin, 2015.

Qu'est-ce que la critique? Suivi de La culture de soi.

KANT, Immanuel. Resposta à pergunta: Que é "Esclarecimento?". IN: Textos Seletos. Ed. Bilíngüe, Rio de Janeiro: Petrópolis, 1974.

LEBRUN, Gérard. A filosofia e sua história. São Paulo: Cosac Naify, 2006.

MACHADO, Roberto.Foucault, a filosofia e a literatura.Rio de Janeiro: Jorge Zahar Ed., 2005.

McKEANE, John. L'absence de livre à venir. IN: Espace Maurice Blanchot; ISSN:

291X<http://www.blanchot.fr/fr/index.php?option=com_content\&task=vie w\&id=246\&Itemid=40\#_ftn2>, acessado em 29 de novembro de 2015.

NIETZSCHE, Friedrich. Escritos sobre história. Rio de Janeiro: Ed. PUC Rio; São Paulo: Loyola, 2005.

PELBART, Peter Pál. Da clausura do fora ao fora da clausura. São Paulo: Iluminuras, 2009. 